\title{
Potential role of recombinant secretory leucoprotease inhibitor in the prevention of neutrophil mediated matrix degradation
}

\author{
Carol G Llewellyn-Jones, David A Lomas, Robert A Stockley
}

\begin{abstract}
Background - Neutrophil elastase is able to degrade connective tissue matrices and is thought to be involved in the pathogenesis of destructive lung diseases.

Methods - The ability of recombinant secretory leucoprotease inhibitor (rSLPI) to inhibit neutrophil mediated degradation of fibronectin in vitro is demonstrated and its efficacy compared with native alpha-1-proteinase inhibitor $\left(n \alpha_{1}-P I\right)$, recombinant alpha-1-proteinase inhibitor $\left(r \alpha_{1}-P I\right)$, and the chemical elastase inhibitor ICI 200355.

Results - When preincubated with neutrophils both rSLPI and $r \alpha_{1}-P I$ were effective inhibitors of fibronectin degradation although $n \alpha_{1}-P I$ and ICI 200355 were less effective. Recombinant SLPI was the most effective inhibitor when the cells were allowed to adhere to fibronectin before the addition of the inhibitors. Preincubation of $\mathrm{rSLPI}(0 \cdot 1 \mu \mathrm{mol} / 1)$ with the fibronectin plate resulted in almost total inhibition of fibronectin degradation (reduced to 3.3 (SE 0.9)\% of control). Pretreating the fibronectin plate with $1 \mu \mathrm{mol} / 1 \mathrm{rSLPI}, \mathrm{r} \alpha_{1}$-PI and ICI 200355 followed by thorough washing before the addition of cells resulted in no inhibition of fibronectin degradation with $r \alpha_{1}-P I$ and the ICI inhibitor, but rSLPI retained its inhibitory effect. This effect could be reduced by adding rSLPI in high $\mathrm{pH}$ buffer or $2 \mathrm{~mol} / 1 \mathrm{NaCl}$.

Conclusions - It is postulated that rSLPI binds to fibronectin to form a protective layer which prevents its degradation by neutrophil elastase. It may prove to be the most useful therapeutic agent in the prevention of neutrophil mediated lung damage.
\end{abstract}

(Thorax 1994;49:567-572)

Neutrophil elastase has been implicated in the pathogenesis of several chronic destructive lung diseases because of its ability to produce, in vitro and in vivo, many of the pathological features associated with these conditions. The enzyme is able to damage ciliated epithelium, ${ }^{1}$ reduce ciliary beating, ${ }^{2}$ induce mucus gland hyperplasia ${ }^{3}$ and mucus secretion, ${ }^{4}$ all of which are features of chronic bronchitis. Furthermore, it can digest lung connective tissue ${ }^{56}$ and this is thought to be responsible for the devel- opment of emphysema in animal models ${ }^{7}$ and man. ${ }^{8}$

The exact mechanisms involved in the development of these diseases are unknown, although neutrophil recruitment and the release of elastase near the connective tissues and into the airways plays an important part. Neutrophils also secrete other proteinases such as cathepsin $G$ and proteinase $C$ which are able to degrade connective tissues. Previous studies have shown, however, that fibronectin solubilisation by neutrophils is largely caused by neutrophil elastase and not cathepsin G. ${ }^{9}$ Because of this central role of neutrophil elastase in the development of chronic lung disease there has been increasing interest in the development and potential therapeutic role of elastase inhibitors in the prevention of progressive lung damage.

Native and recombinant proteinase inhibitors have been used for preliminary studies and have been shown to inhibit elastase activity within the airways. ${ }^{10-13}$ In addition, chemical inhibitors of neutrophil elastase have been developed which influence the development of chronic bronchitis and emphysema in animal models, ${ }^{1415}$ and therapeutic studies with these inhibitors are under way.

For any agent to be a realistic therapeutic option it must be capable of influencing the elastase load in the lung in a way which will alter the pathogenesis of the disease. The introduction of an effective inhibitor into the airways should reduce the elastase load on the epithelium thereby reducing bronchial damage. The inhibitor should interact irreversibly with neutrophil elastase, however, since reversible neutrophil elastase/inhibitor complexes may increase interstitial damage leading to emphysema. ${ }^{1516}$

Once in the lung the neutrophil becomes tightly adherent to connective tissues and can release neutrophil elastase into the microenvironment between the cell and substrate. Tissue destruction in this privileged site is remarkably resistant to the effects of proteinase inhibitors. ${ }^{6}$ Previous in vitro studies suggest that secretory leucoprotease inhibitor (SLPI) may be the most effective inhibitor as it is able to gain access to this privileged site, probably because of its relatively small molecular size $(12 \mathrm{kDa})$, and it is therefore more effective at inhibiting proteolysis by adherent neutrophils. ${ }^{1718}$ Studies have shown that SLPI is associated with lung elastin and thus may protect it against digestion by neutrophil elastase. ${ }^{19}$

The aim of the present study, therefore, was to assess the potential role of rSLPI in the 
prevention of progression of chronic destructive lung diseases by, firstly, comparing its efficacy with other proteinase inhibitors native and recombinant alpha-1-proteinase inhibitor $\left(\alpha_{1}-\mathrm{PI}\right)$ and the synthetic elastase inhibitor ICI 200355 - and, secondly, by clarifying further the mechanism by which rSLPI inhibits neutrophil mediated degradation of connective tissue.

\section{Methods \\ FUNCTION OF INHIBITORS}

The specific activities of the inhibitors rSLPI (gift from $\mathrm{Dr} R$ Thompson, Synergen, Boulder, USA), $n \alpha_{1}$-PI purified from human plasma, ${ }^{20} \mathrm{r} \alpha_{1}$-PI (gift from Dr H P Schnebli, Ciba-Geigy), and ICI 200355 (gift from Dr M Glass, ICI, USA) were confirmed by their ability to inhibit neutrophil elastase of known activity. In brief, $30 \mu \mathrm{l}$ samples of inhibitors at increasing concentration were incubated with an equal volume of neutrophil elastase $(0.33 \mu \mathrm{mol} / \mathrm{l})$ for 30 minutes at $37^{\circ} \mathrm{C}$ before the addition of elastase substrate (succinyl-ala-alaala-pNa, Sigma Chemicals, Dorset, UK) at $1 \mathrm{mg} / \mathrm{ml}$. Following an incubation period of one hour the absorbance at $410 \mathrm{~nm}$ was measured. The decrease in enzyme activity was compared with inhibitor concentration and a regression line constructed. The intercept was taken as the amount of inhibitor required to inhibit all of the neutrophil elastase. Assuming a 1:1 enzyme/inhibitor complex, the amount taken to inhibit each micromol of neutrophil elastase was taken as the micromolar activity of the inhibitor. This value was used for all subsequent assays.

\section{ISOLATION OF BLOOD NEUTROPHILS}

Neutrophils were isolated using the method of Jepsen and Skottun. ${ }^{21}$ Briefly, venous blood from normal healthy subjects was collected into lithium heparin tubes. Each sample was diluted with an equal volume of $0.15 \mathrm{~mol} / \mathrm{l}$ sodium chloride and layered onto a Percoll gradient (Sigma Chemicals, Dorset, UK). The top layer consisted of $2 \mathrm{ml} \mathrm{54 \%} \mathrm{Percoll} \mathrm{(den-}$ sity $1.075 \mathrm{~g} / \mathrm{ml}$ ) and the lower layer of $3 \mathrm{ml}$ $78 \%$ Percoll (density $1.096 \mathrm{~g} / \mathrm{ml}$ ). The tubes were centrifuged for 25 minutes at $200 \mathrm{~g}$ at room temperature. The neutrophils $(>96 \%$ pure, $>98 \%$ viable) were harvested from the interface of the $54 \%$ and $78 \%$ layers, washed twice in $0.15 \mathrm{~mol} / 1$ saline solution, counted, and resuspended at the required concentration in RPMI 1640 medium for assessment of extracellular proteolysis (Flow Laboratories, Rickmansworth, UK). All reagents were confirmed to contain less than $20 \mathrm{ng} / \mathrm{l}$ endotoxin activity using the KabiVitrum Coat test (Flow Laboratories, Rickmansworth, UK).

\section{EXTRACELLULAR PROTEOLYSIS}

Degradation of fibronectin was assessed using the method of Campbell et $a l^{6}$ modified by
Burnett et al..$^{22}$ Purified human fibronectin was obtained from the Sigma Chemical Co (Poole, Dorset, UK) and iodinated by the chloramine$\mathrm{T}$ method with sodium ${ }^{125}$ iodide (ICN Flow, High Wycombe, Bucks, UK). The radiolabelled fibronectin was diluted with unlabelled fibronectin in $0.05 \mathrm{~mol} / 1$ carbonate/bicarbonate buffer $(\mathrm{pH} \mathrm{9.6)}$ to give $2000 \mathrm{cpm} / \mu \mathrm{g}$ fibronectin and dispensed into the wells of microtitre plates at $30 \mu \mathrm{g} / \mathrm{well}$. The plates were allowed to dry at $37^{\circ} \mathrm{C}$ and then washed three times with phosphate buffered saline ( $\mathrm{pH} \mathrm{7 \cdot 2)}$. The isolated neutrophils suspended in RPMI medium $\left(3 \times 10^{5}\right.$ cells $/$ well $)$ were dispensed into the wells and the plates incubated at $37^{\circ} \mathrm{C}$ in a humidified atmosphere of $5 \%$ carbon dioxide $/ 95 \%$ air for three hours. After incubation the supernatant was collected from the wells and the degraded fibronectin was assessed by counting with an LKB Multigamma II gamma counter. The ${ }^{125} \mathrm{I}$ counts in the supernatants of wells containing RPMI medium alone (blank) were deducted from those containing neutrophils. All experiments were performed in the absence (resting) and presence (stimulated cells) of $1 \mu \mathrm{mol} / 1 \mathrm{~F}-\mathrm{Met}-$ Leu-Phe (FMLP) and the result for each assay was determined from the mean value for three replicate wells.

The experiments were performed in three ways: (1) cells were preincubated with the inhibitors at varying concentrations for 30 minutes before being added together onto the fibronectin plate (preincubation); (2) cells and inhibitors were added to the fibronectin simultaneously (coincubation); and (3) the cells were allowed to adhere onto the fibronectin for 30 minutes followed by the inhibitors (adherent cells). The results obtained for the adherent cells were corrected for the 30 minutes before the addition of the inhibitors.

The effect of pretreating the fibronectin plates with the inhibitors before the addition of cells was also assessed. This was again performed in three ways: (1) the inhibitors at $0.1 \mu \mathrm{mol} / 1$ concentration in RPMI medium were added to the fibronectin and incubated at $37^{\circ} \mathrm{C}$ for 30 minutes before the addition of cells; (2) the inhibitors rSLPI, r $\alpha_{1}-\mathrm{PI}$, and ICI $200355(0.1 \mu \mathrm{mol} / 1$ and $1.0 \mu \mathrm{mol} / \mathrm{l})$ were added to the fibronectin, incubated at $37^{\circ} \mathrm{C}$ for one hour, washed three times with RPMI medium, followed by addition of the neutrophils; and (3) $\mathrm{rSLPI}$ at $1 \mu \mathrm{mol} / 1$ concentration was dissolved in either RPMI medium of increasing $\mathrm{pH}$ from $\mathrm{pH} 7.4$ to 12.5 , or in $2 \mathrm{~mol} / 1 \mathrm{NaCl}$ solution. The rSLPI in the varying buffers was pipetted onto the fibronectin plate and incubated for one hour at $37^{\circ} \mathrm{C}$ followed by three washes with RPMI medium at $\mathrm{pH} 7.4$ to restore neutral $\mathrm{pH}$. Following the washes and restoration of neutral $\mathrm{pH}$ the neutrophils were dispensed onto the fibronectin plates and the assay performed as usual. All experiment wells were repeated with three replicates and the value for each experiment taken as the mean. The effect of $\mathrm{pH}$ on the subsequent function of rSLPI was assessed by returning the solution to neutral $\mathrm{pH}$ and assessing the inhibitory activity as above. 
Table 1 Inhibition of fibronectin degradation, by resting and stimulated neutrophils, in the presence of $r S L P I(p<0.0001), n \alpha,-P I(p<0.0002)$, and $r \alpha,-P I(p<0.0001)$ when preincubated with neutrophils or added to adherent neutrophils. The mean ( $S E)$ data are the remaining amount of fibronectin degraded presented as a percentage of control values, where control is the amount of fibronectin degraded in the absence of inhibitor

\begin{tabular}{|c|c|c|c|c|}
\hline & \multicolumn{2}{|c|}{ Preincubated with cells } & \multicolumn{2}{|c|}{ Adherent cells } \\
\hline & Resting & Stimulated & Resting & Stimulated \\
\hline $\begin{array}{l}\text { rSLPI } \\
0.01 \mu \mathrm{mol} / 1 \\
0.1 \mu \mathrm{mol} / 1 \\
1.0 \mu \mathrm{mol} / 1\end{array}$ & $\begin{array}{l}46 \cdot 7(9 \cdot 4) \\
18 \cdot 7(3.3) \\
16 \cdot 1(3.2)\end{array}$ & $\begin{array}{l}89.9(2.7) \\
30 \cdot 1(7 \cdot 1) \\
29.0(2.0)\end{array}$ & $\begin{array}{l}80.8(7 \cdot 7) \\
51.0(6.2) \\
23.0(3.9)\end{array}$ & $\begin{array}{l}79 \cdot 0(5 \cdot 7) \\
49 \cdot 0(11 \cdot 1) \\
23 \cdot 0(2 \cdot 5)\end{array}$ \\
\hline $\begin{array}{l}\mathrm{r} \alpha_{1}-\mathrm{PI} \\
0.01 \mu \mathrm{mol} / 1 \\
0.1 \mu \mathrm{mol} / 1 \\
1.0 \mu \mathrm{mol} / 1\end{array}$ & $\begin{array}{l}47 \cdot 0(16 \cdot 0) \\
20 \cdot 0(5 \cdot 8) \\
16 \cdot 1(6 \cdot 3)\end{array}$ & $\begin{array}{l}79 \cdot 5(4 \cdot 3) \\
35 \cdot 0(2 \cdot 9) \\
18 \cdot 7(4 \cdot 9)\end{array}$ & $\begin{array}{l}76.4(2.9) \\
71: 0(3.4) \\
45 \cdot 0(4 \cdot 3)\end{array}$ & $\begin{array}{l}75 \cdot 0(6 \cdot 6) \\
55 \cdot 0(4 \cdot 3) \\
49 \cdot 0(2 \cdot 1)\end{array}$ \\
\hline $\begin{array}{l}\mathrm{n} \alpha_{1}-\mathrm{PI} \\
0.01 \mu \mathrm{mol} / 1 \\
0.1 \mu \mathrm{mol} / 1 \\
1.0 \mu \mathrm{mol} / 1\end{array}$ & $\begin{array}{l}71.4(6.4) \\
59.6(6.6) \\
51.9(4.9)\end{array}$ & $\begin{array}{l}81.8(5.8) \\
66.0(7.9) \\
55.0(5.5)\end{array}$ & $\begin{array}{l}71.7(4.6) \\
63.5(6.5) \\
66.9(3.8)\end{array}$ & $\begin{array}{l}86.9(5.2) \\
69.2(9.8) \\
63.9(3.5)\end{array}$ \\
\hline
\end{tabular}

Table 2 Inhibition of fibronectin degradation by resting and stimulated neutrophils in the presence of ICI 200355 when preincubated with neutrophils $(p<0.0001)$ or added to neutrophils adherent to fibronectin $(p<0.0001)$. Mean $(S E)$ data are the remaining amount of fibronectin degraded presented as a percentage of control values, where control is the amount of fibronectin degraded in the absence of inhibitor

\begin{tabular}{|c|c|c|c|c|}
\hline \multirow{2}{*}{$\begin{array}{l}\text { ICI } 200355 \\
\text { concentration }\end{array}$} & \multicolumn{2}{|c|}{ Preincubated with cells } & \multicolumn{2}{|c|}{ Adherent cells } \\
\hline & Resting & Stimulated & Resting & Stimulated \\
\hline $\begin{array}{l}10^{-8} \mathrm{~mol} / 1 \\
10^{-7} \mathrm{~mol} / 1 \\
10^{-6} \mathrm{~mol} / 1 \\
10^{-5} \mathrm{~mol} / 1 \\
10^{-4} \mathrm{~mol} / 1 \\
10^{-3} \mathrm{~mol} / 1\end{array}$ & $\begin{array}{l}82.0(7.4) \\
81.3(5.8) \\
66.0(2.1) \\
37.5(3.8) \\
28.0(3.6) \\
23.5(3.9)\end{array}$ & $\begin{array}{l}86.0(2.2) \\
81.3(6.1) \\
67.0(4.7) \\
43.5(3.8) \\
31.0(1.9) \\
30.8(1.9)\end{array}$ & $\begin{array}{l}95.0(3.0) \\
90.3(4.9) \\
76.5(6.9) \\
37.0(6.9) \\
28.5(6.5) \\
31.0(4.4)\end{array}$ & $\begin{array}{l}84.9(7.7) \\
79.5(6.6) \\
55.4(7.5) \\
38.5(7.0) \\
37.0(5.2) \\
29.8(5 \cdot 1)\end{array}$ \\
\hline
\end{tabular}

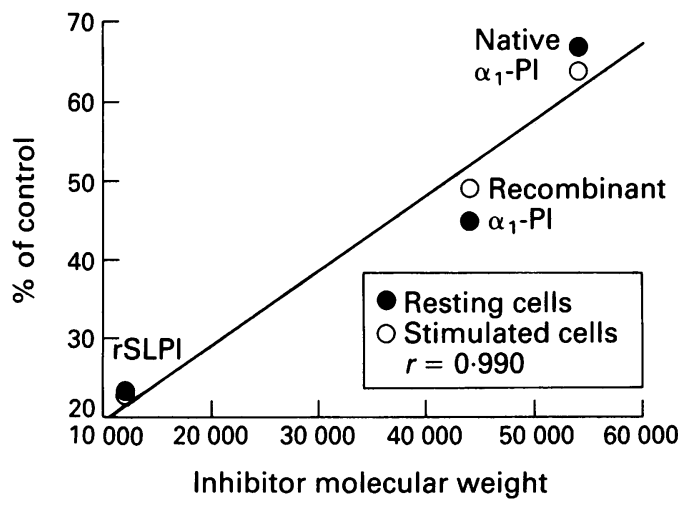

Figure 1 Relation between the molecular size of recombinant SLPI, recombinant $\alpha_{1}-P I$ and native $\alpha_{1}-P I$ and their ability to inhibit fibronectin degradation by resting and stimulated neutrophils adherent to

fibronectin. Data are presented as percentage of control values in the absence of inhibitor.
Table 3 Comparison of the effects of elastase inhibitors at $0 \cdot 1 \mu \mathrm{mol} / \mathrm{l}$ on fibronectin degradation by resting cells when added to neutrophils adherent to fibronectin (adherent cells), preincubated with neutrophils before the assay (preincubation), or when added to fibronectin before the neutrophils (pretreatment). Mean (SE) data are the remaining fibronectin degradation presented as a percentage of control values, where control is the amount of fibronectin degraded in the absence of inhibitors

\begin{tabular}{|c|c|c|c|}
\hline Inhibitor & Adherent cells & Preincubation & Pretreatment \\
\hline $\begin{array}{l}n \alpha_{1}-\mathrm{PI} \\
\text { r } \alpha_{1}-\mathrm{PI} \\
\text { rSLPI } \\
\text { ICI } 200355\end{array}$ & $\begin{array}{l}67.9(3.8) \\
71.0(3.4) \\
51.0(6.2) \\
90.6(4 \cdot 6)\end{array}$ & $\begin{array}{l}60.6(6 \cdot 6) \\
20 \cdot 0(5 \cdot 8) \\
18 \cdot 0(3 \cdot 3) \\
82.5(6.3)\end{array}$ & $\begin{array}{c}37.6(6.9) \\
36.0(9.5) \\
3.3(0.89) \\
71.0(3.3)\end{array}$ \\
\hline
\end{tabular}

DATA ANALYSIS

Statistical analyses of the effect of the elastase inhibitors on neutrophil degradation of fibronectin were performed using ANOVA and analyses comparing inhibitors performed using the Student's $t$ test.

\section{Results}

CELL VIABILITY

The viability of the neutrophils was not altered following incubation with any of the inhibitors - that is, $>98 \%$ viable - as assessed by exclusion of trypan blue solution.

\section{FIBRONECTIN PROTEOLYSIS}

All four inhibitors inhibited fibronectin degradation (by resting cells and by cells stimulated by $1 \mu \mathrm{mol} / 1$ FMLP) in a dose dependent manner when preincubated with neutrophil, coincubated with neutrophils (added to fibronectin at the same time), or when added to neutrophils adherent to the fibronectin. The results are summarised in tables 1 and 2 . The effects of preincubation and coincubation were similar and therefore only the preincubation results have been included. When the inhibitors were preincubated with neutrophils similar results were achieved with rSLPI and $r \alpha_{1}-\mathrm{PI}$, but both were more effective than $\mathrm{n} \alpha_{1}-\mathrm{PI}$ and ICI $200355(\mathrm{p}<0.001)$ at comparable molar concentrations. When the inhibitors were added to neutrophils adherent to fibronectin, however, rSLPI was significantly more effective at inhibiting fibronectin degradation than the equivalent concentrations of both $n \alpha_{1}-P I$ and $r \alpha_{1}-P I(p<0.01)$. Figure 1 shows the relation between the molecular size of the natural proteinase inhibitors and efficiency at inhibiting fibronectin degradation by adherent neutrophils ( $n=4$ for each point).

In a further series of experiments the inhibitors (at $0 \cdot 1 \mu \mathrm{mol} / \mathrm{l}$ ) were added to the fibronectin plates for 30 minutes before the addition of the cells (pretreatment). Table 3 summarises the results gained from this latter experiment and compares the results obtained with those when the inhibitors were added to cells already adherent to the fibronectin or preincubated for 30 minutes with neutrophils before the assay.

The effect of pretreatment of the fibronectin with 0.1 and $1.0 \mu \mathrm{mol} / 1$ concentrations of $\mathrm{r} \alpha_{1}$ PI, rSLPI, and the ICI inhibitor followed by extensive washing is shown in fig 2. Despite the washing rSLPI was still able to inhibit fibronectin degradation to $20 \cdot 8$ (SE $5 \cdot 3$ ) $\%$ of control (resting cells) at $0 \cdot 1 \mu \mathrm{mol} / 1 \mathrm{rSLPI}$ and to $8.7(0.84) \%$ at $1.0 \mu \mathrm{mol} / \mathrm{l}$.

The effect of pretreating the fibronectin plates with $1 \mu \mathrm{mol} / 1 \mathrm{rSLPI}$ in RPMI of increasing $\mathrm{pH}$, and $2 \mathrm{~mol} / \mathrm{l} \mathrm{NaCl}$ solution (followed by washing and restoration of neutral $\mathrm{pH}$ before the addition of neutrophils) is shown in fig 3. As the $\mathrm{pH}$ of the original buffer was increased and when rSLPI was dissolved in $2 \mathrm{~mol} / 1 \mathrm{NaCl}$ solution the subsequent efficiency of the rSLPI to inhibit fibronectin degradation by neutrophils was reduced. 


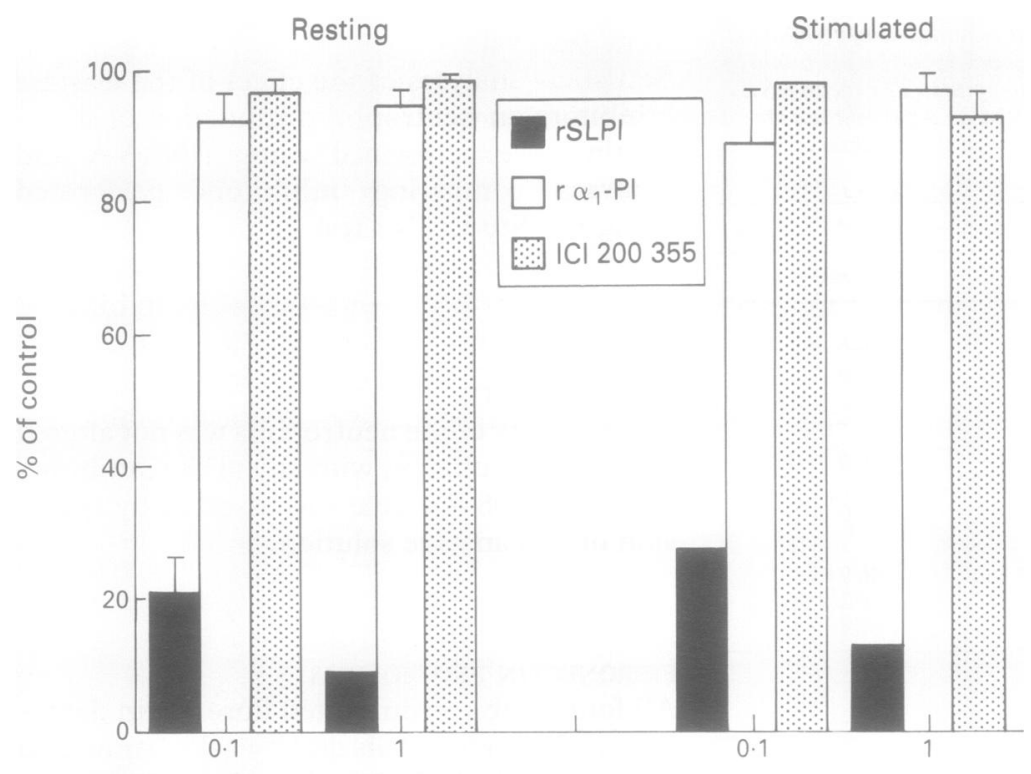

Concentration of inhibitor ( $\mu \mathrm{mol} / \mathrm{l})$

Figure 2 Effect of $0 \cdot 1 \mu \mathrm{mol} / \mathrm{l}$ and 1.0 $\mu \mathrm{mol} / \mathrm{l}$ rSLPI, r $\alpha_{1}-P I$, and ICI 200355 pretreatment of fibronectin (followed by extensive washing) on fibronectin degradation by resting cells and cells stimulated with 1 umol/l FMLP. Data are expressed as a percentage of control values where control is the amount of fibronectin degradation by neutrophils in wells pretreated with RPMI medium. Each histogram represents the mean $(S E)$ of three replicates.

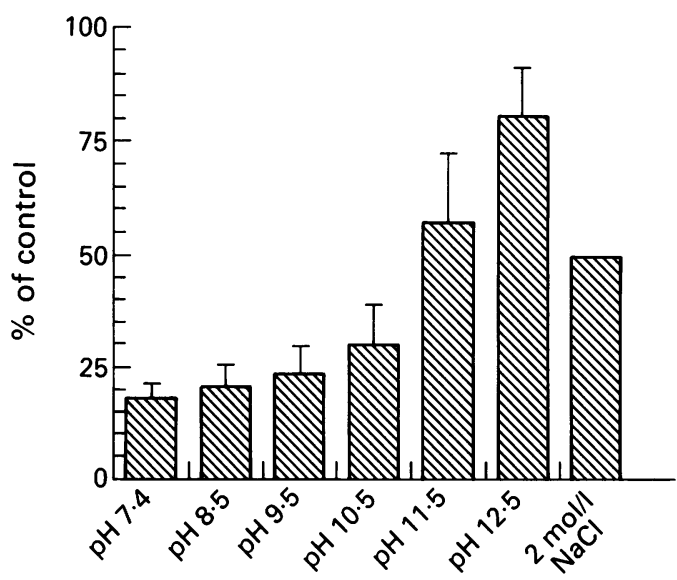

$1 \mu \mathrm{mol} / / \mathrm{rSLPI}$

Figure 3 Effect of pretreating fibronectin wells with 1 umol/l $r S L P I$ in buffer of increasing $\mathrm{pH}(\mathrm{pH} 7.4$ to 12.5 ) or 2 mol/l $\mathrm{NaCl}$ solution on neutrophil degradation of fibronectin. The rSLPI was incubated with the fibronectin for one hour followed by washing and restoration of neutral $p H$ before the addition of neutrophils. Data are presented as a percentage of the control values, control being neutrophil degradation of fibronectin following pretreatment of fibronectin with buffer alone. Each histogram represents the mean $(S E)$ of four experiments.

\section{Discussion}

This study evaluated the potency of rSLPI, compared with $n \alpha_{1}-P I, r \alpha_{1}-P I$, and the synthetic ICI inhibitor, to inhibit neutrophil extracellular proteolysis of fibronectin. The results presented show that rSLPI is the most potent inhibitor of neutrophil mediated fibronectin degradation, and is able to inhibit the process in a dose dependent manner whether preincubated with cells or added to adherent cells. The recombinant form of $\alpha_{1}-\mathrm{PI}\left(\mathrm{r} \alpha_{1}-\mathrm{PI}\right)$ is also an effective inhibitor of fibronectin degradation by neutrophils when preincubated with the cells before the assay, but when the cells had become adherent $r \alpha_{1}$-PI was less able to reduce fibronectin degradation.

The native form of $\alpha_{1}$-PI purified from human plasma was relatively ineffective at limiting fibronectin degradation by neutrophils when preincubated with them, and was even less effective when the neutrophils were allowed to become adherent. Although other workers ${ }^{6}$ have reported greater levels of inhibition using $n \alpha_{1}-\mathrm{PI}$ in a similar assay system with up to $79 \cdot 8$ (SD 6.3 ) \% inhibition of fibronectin degradation by adherent neutrophils compared with $33.1 \%$ inhibition in our assay, this can be explained by differences in the concentrations used $(1 \mu \mathrm{mol} / 1$ in our assay $v$ a calculated concentration of $\left.>4 \mu \mathrm{mol} / 1^{6}\right)$. We cannot fully explain why the $n \alpha_{1}$-PI was less effective than $\mathrm{r} \alpha_{1}$-PI at inhibiting fibronectin proteolysis as the concentrations used $(0 \cdot 01-1 \mu \mathrm{mol} / \mathrm{l})$ were based on functional activity. It may be partly related, however, to the smaller size of $\mathrm{r} \alpha_{1}$-PI (due to lack of glycosylation). Alpha $a_{1}$ PI is thought to be excluded from the privileged site between neutrophils and fibronectin into which the neutrophil elastase is released and where proteolysis occurs. ${ }^{6}$ Our studies showing a reduction in the efficacy of $\alpha_{1}$-PI when cells are allowed to adhere first would support this concept. It may be, therefore, that the smaller size of $r \alpha_{1}-\mathrm{PI}(45000 \mathrm{Da})$ enables it to penetrate this privileged site more effectively than the native protein $(54000 \mathrm{Da})$.

This concept is partly supported by the results with rSLPI. Recombinant SLPI has an even smaller molecular mass (12000 Da) and may be able to gain access to the subcellular space of the adherent neutrophils more easily, thus explaining its comparable effectiveness at $1 \mu \mathrm{mol} / 1$ in limiting fibronectin degradation by both non-adherent and adherent cells. Other workers have also shown that rSLPI, unlike $\alpha_{1}-\mathrm{PI}$, is able to protect connective tissue from degradation by adherent neutrophils. ${ }^{1718}$ In particular, Rice and Weiss ${ }^{17}$ reported that rSLPI was able to protect subjacent substrates from degradation by adherent neutrophils whereas plasma (containing $\alpha_{1}-\mathrm{PI}$ ) was ineffective. When the neutrophils were prevented from becoming adherent, however, both inhibitors were equally effective. Using high concentrations of $\mathrm{rSLPI}(8.5 \mu \mathrm{mol} / \mathrm{l})$ the authors were able to obtain $93 \%$ inhibition of fibronectin degradation and $88.5 \%$ inhibition of degradation of elastin by adherent neutrophils. The authors suggested that rSLPI may be exerting a protective effect by gaining access to proteolytic zones inaccessible to other inhibitors. Stolk et al, ${ }^{18}$ in a more recent study, have shown that in a cell free system native SLPI and $\alpha_{1}$-PI were of equal potency at inhibiting neutrophil elastase, yet when cells were adherent to fibrinogen SLPI was more effective.

The results of these studies and those presented here suggest that the molecular size of the inhibitor is a determinant of its efficacy when neutrophils are tightly adherent to a substrate as illustrated in fig 1 . The molecular 
size of the inhibitor is clearly not the only factor, however, as the small synthetic ICI inhibitor $(685 \mathrm{Da})$ which should be most able to penetrate the cell substrate interface was less effective than even the larger protein inhibitors at limiting degradation of fibronectin by adherent neutrophils. These results suggest that the efficacy of rSLPI may not be simply a feature of its small molecular size.

Neutrophils are capable of releasing proteinases other than neutrophil elastase, such as cathepsin $G$ and proteinase 3 , into the subcellular space. The ICI inhibitor is a specific elastase inhibitor without any inhibitory effect on cathepsin $G$ and proteinase 3. If these enzymes were contributing to the degradation of fibronectin the ICI inhibitor would therefore be expected to appear less effective than rSLPI and $r \alpha_{1}-P I$. Previous studies characterising the degradation of fibronectin by neutrophils have found similar degradation products to those produced by pure neutrophil elastase. ${ }^{9}$ In addition, specific cathepsin $\mathrm{G}$ chloromethylketones were unable to inhibit neutrophil mediated fibronectin degradation, suggesting that cathepsin G was not important in proteolysis. Recent studies have shown that SLPI does not have any inhibitory effect on proteinase $3^{23}$ and, since SLPI inhibits fibronectin degradation by neutrophils, this provides further indirect support for the conclusion that fibronectin degradation by neutrophils is largely due to elastase. The ICI inhibitor would therefore be expected to be at least as effective as SLPI at inhibiting neutrophil mediated degradation of fibronectin if the size of the inhibitor is a critical factor in its efficacy.

The relative ineffectiveness of the ICI inhibitor suggests that factors other than size are also of major importance. This was confirmed by the experiments in which we showed that rSLPI was even more effective when added to the fibronectin plate before the cells, achieving $>96 \%$ inhibition, whereas there was no further increase in inhibition by $r \alpha_{1}-\mathrm{PI}$ or the ICI inhibitor (see results).

Previous studies have suggested that rSLPI can associate with elastin ${ }^{19}$ and act as an inhibitor coat which prevents degradation by neutrophil elastase bound to the elastin. ${ }^{24}$ In order to investigate the possibility that rSLPI was binding to the fibronectin we designed a further series of experiments in which fibronectin plates were incubated with 0.1 and $1 \mu \mathrm{mol} / 1$ solutions of $\mathrm{rSLPI}, \mathrm{r} \alpha_{1}-\mathrm{PI}$, or the ICI inhibitor for one hour followed by extensive washing. Following the washing the wells that had received $r \alpha_{1}-P I$ and the ICI inhibitor were unable to inhibit fibronectin degradation by neutrophils, indicating that the inhibitor had been removed (fig 2). The rSLPI wells still showed $>90 \%$ inhibition at $1 \mu \mathrm{mol} / 1$, however, suggesting that rSLPI had bound to the fibronectin. Recombinant SLPI is a highly cationic protein with a high isoelectric point $(>9)$, so binding to connective tissue matrix such as fibronectin is likely to involve ionic bonds. To investigate this possibility we designed experiments to interfere with ionic bonding. RPMI medium of increasing $\mathrm{pH}$ containing $1 \mu \mathrm{mol} / 1 \mathrm{rSLPI}$ or $\mathrm{rSLPI}$ in $2 \mathrm{~mol} / 1$ $\mathrm{NaCl}$ solution reduced the effectiveness of rSLPI, presumably by preventing binding to the fibronectin (fig 3). The negative charges in the alkaline buffer would interfere with binding of rSLPI by neutralising its positive charges and thus inhibiting ionic bonding. A similar effect was seen with rSLPI in high salt solution, where there was also a reduction in the efficacy of rSLPI in the prevention of fibronectin degradation by neutrophils suggesting a reduction in rSLPI binding to fibronectin (by the negative chloride ions). To exclude the possibility that the high $\mathrm{pH}$ buffer was denaturing rSLPI and thereby reducing its inhibitory function we incubated the inhibitor for one hour in buffers of increasing $\mathrm{pH}$ as above. After restoration of neutral $\mathrm{pH}$ the activity of the inhibitor was titrated against pure neutrophil elastase as previously described and confirmed to be fully functional (data not shown). Finally, to investigate the remaining possibility that rSLPI bound to fibronectin could have interfered with adherence of neutrophils onto the fibronectin (and hence its degradation) we performed an adherence assay comparing untreated fibronectin with fibronectin pretreated with rSLPI. Neutrophils were allowed to adhere to fibronectin for 30 minutes followed by thorough washing and counting. The experiments were performed six times and cell adherence was confirmed to be unaltered by rSLPI (data not shown)

The results presented here have shown a unique advantage of rSLPI over the other inhibitors studied. Although SLPI is a reversible inhibitor, kinetic measurements have shown that it very rapidly forms a highly stable complex with neutrophil elastase $\left(\mathrm{k}_{\mathrm{ass}}=6.4 \times 10^{6} / \mathrm{M} / \mathrm{s} ; \quad \mathrm{k}_{\mathrm{diss}}=2.3 \times 10^{-3} / \mathrm{s}\right) \quad$ and thus it is termed a pseudoreversible inhibitor of neutrophil elastase. We postulate, in accordance with other workers, that rSLPI is better able to gain access to the interface between neutrophils and extracellular matrix when the neutrophils are adherent, ${ }^{61718}$ but further that they are able to coat connective tissue matrices such as fibronectin by ionic binding thus preventing their degradation by neutrophil elastase. This would support the suggestions of other workers that SLPI plays a part in protecting elastin fibres from elastase mediated degradation. ${ }^{19}$ This inhibitor may therefore have a major advantage over the others if the therapeutic aim is to prevent connective tissue degradation in diseases such as emphysema. However, a recent study has shown that native $\alpha_{1}-\mathrm{PI}$ is able to bind in vitro to extracellular matrix composed of $51 \%$ glycoproteins, $37 \%$ collagen, and $12 \%$ elastin. ${ }^{25}$ The authors report that the $\alpha_{1}$-PI was not binding to the glycoproteins as removal of these from the matrix did not affect the binding to the rest of the matrix. It seems probable that the $\alpha_{1}-P I$ was binding to the collagen (as previous studies have found SLPI but not $\alpha_{1}$-PI in association with elastin ${ }^{19}$ ) thereby preventing its breakdown by neutrophil elastase. This work would be consistent with our data showing 
that $\mathrm{r} \alpha_{1}-\mathrm{PI}$ is unable to bind to the glycoprotein fibronectin.

Recombinant SLPI and r $\alpha_{1}$-PI were both effective inhibitors of fibronectin digestion when preincubated with neutrophils (as in the circulation), but when cells are adherent to connective tissue (as in the interstitium) rSLPI was the best inhibitor, probably because of its ability to form a protective layer thus denying active neutrophil elastase access to connective tissues. Our data suggest an important role for rSLPI as a therapeutic agent in the protection of lung connective tissues. Further studies in vivo with this inhibitor are therefore required.

There has been much interest in augmentation therapy with $\alpha_{1}$-PI for subjects with $\alpha_{1}$ PI deficiency by systemic administration ${ }^{10}$ and by inhalation in patients with cystic fibrosis. ${ }^{11}$ Our results show that rSLPI may be a more effective inhibitor in this situation and also in the prevention or treatment of smoking related emphysema and bronchitis in the absence of $\alpha_{1}$-PI deficiency.

The writers acknowledge the financial support provided by Glaxo Group Research Ltd, the British Lung Foundation, and the General Hospital Bicentenary Appeal. DL is an MRC training fellow. We thank Dr D Burnett for his helpful comments on the manuscript.

1 Tegner H, Ohlsson K, Torelman NG. Effect of human leucocyte elastase on tracheal mucosa and its mucociliary activity. Rhinology 1979;17:199-206.

2 Smallman LA, Hill SL, Stockley RA. Reduction of ciliary beat frequency in vitro by sputum from patients with bronchiectasis: a serine proteinase effect. Thorax 1984;39:663-7.

3 Snider GR, Schur PH, Lucey EC. Eglin-C, a polypeptide derived from the medicinal leech prevents human neutrophil elastase-induced emphysema and bronchial gland secretory cell metaplasia in the hamster. Am Rev Respir Dis 1985;132:1155-61.

4 Bruer R, Christensen TG, Niles RM, Stone PJ, Snider GL. Human neutrophil elastase causes glycoconjugate release Human neutrophil elastase causes glycoconjugate release
from the epithelial cell surface of hamster trachea in organ from the epithelial cell surface of hamster trache
culture. Am Rev Respir Dis 1989;139:779-82.

5 Reilly CF, Travis J. The degradation of human lung elastin by neutrophil proteinases. Biochim Biophys Acta 1980;621:147-57?

6 Campbell EJ, Senior RM, McDonald JA, Cox DL. Proteolysis by neutrophils. Relative importance of cell-substrate contact and oxidative inactivation of proteinase inhibitors in vitro. $\mathcal{F}$ Clin Invest 1982;70:845-52.

7 Senior RM, Tegner H, Kuhn C, Ohlsson K, Starcher B, Pierce JA. The induction of pulmonary emphysema with human leucocyte elastase. Am Rev Respir Dis 1977; human leucoci

8 Kuhn C, Senior RM. The role of elastases in the development of emphysema. Lung 1978;177(Suppl 432):1-85.
9 Chamba A, Afford SC, Stockley RA, D Burnett. Extracellular proteolysis of fibronectin by neutrophils: characterization and the effects of recombinant cytokines. $A m \mathcal{F}$ Respir Cell Mol Biol 1991;4:330-7.

10 Hubbard RC, Sellers S, Czerski D, Stephens L, Crystal RG. Biochemical efficacy and safety of monthly augmentation therapy for $\alpha_{1}$-antitrypsin deficiency. $\mathcal{f} A M A$ 1988;260:1259-64.

11 McElvaney NG, Hubbard RC, Birrer P, Cherniak MS, Caplan DB, Frank MM, et al. Aerosol $\alpha_{1}$-antitrypsin treatment for cystic fibrosis. Lancet 1991;337:392-4.

12 Birrer P, McElvaney NG, Gillissen A, Bloedow DC, Hubbard DC, Crystal RG. Intravenous recombinant secretory leukoprotease inhibitor augments anti-neutrophil elastase defense. F Appl Physiol. 1992;73:317-23.

13 Lucey EC, Stone PJ, Ciccolela DE, Breuer R, Christensen TG, Thompson RC, et al. Recombinant human secretory leucocyte-protease inhibitor: in vitro properties, and amelioration of human neutrophil elastase-induced emphysema and secretory cell metaplasia in the hamster. f Lab Clin Med 1990;115:224-32.

14 Stone PJ, Lucey EC, Snider GL. Induction and exacerbation of emphysema with human neutrophil elastase inactivated reversibly by a peptide boronic acid. $\mathrm{Am} \mathrm{Rev}$ Respir Dis 1990;141:46-52.

15 Davies P, Ashe BM, Bonney RJ, Dorn C, Finke P, Fletcher $\mathrm{D}$, et al. The discovery and biologic properties of cephalosporin-based inhibitors of PMN elastase. Ann NY Acad Sci 1991;624:219-99.

16 Padrines M, Bieth JG. Elastin decreases the efficiency of neutrophil elastase inhibitors. Am $\mathcal{F}$ Respir Cell $\mathrm{Mol}$ Biol 1991;4:187-93.

17 Rice WG, Weiss SJ. Regulation of proteolysis at the neutrophil-substrate interface by secretory leucoprotease inhibitor. Science 1990;249:178-81.

18 Stolk J, Davies P, Kramps JA, Dijkman JH, Humes J, Knight WB, et al. Potency of antileucoprotease and $\alpha_{1}$ antitrypsin to inhibit degradation of fibrinogen by adherent polymorphonuclear leucocytes from normal subjects and patients with chronic granulomatous disease. $A m \mathcal{F}$ Respir Cell Mol Biol 1992;6:521-6.

19 Kramps JA, Te Boekhorst AH, Franson JA, Ginsel LA, Dijkman JH. Antileukoprotease is associated with elastin fibers in the extracellular matrix of the human lung. $\mathrm{Am}$ Rev Respir Dis 1989;140:471-6.

20 Lomas DA, Evans DLI, Stone SR, Chang W-SW, Carrell $\mathrm{RW}$. The effect of the $\mathrm{Z}$ mutation on the physical and inhibitory properties of $\alpha_{1}$-antitrypsin. Biochemistry 1993;32.2:500-8.

21 Jepsen LV, Skottun T. A rapid one-step method for the isolation of human granulocytes from whole blood. Scand $\mathcal{f}$ Clin Lab Invest 1982;42:235-8.

22 Burnett D, Chamba A, Hill SL, Stockley RA. Neutrophils from subjects with chronic obstructive lung disease show enhanced chemotaxis and extracellular proteolysis. Lancet 1987;ii:1043-6.

23 Rao NV, Marshall BC, Gray BH, Hoidal JR. Interaction of secretory leukocyte protease inhibitor with proteinase-3. Am $\mathcal{f}$ Respir Cell Mol Biol 1993;8:612-6.

24 Morrison HM, Welgus GW, Stockley RA, Burnett D, Campbell EJ. Inhibition of human leucocyte elastase bound to elastin: relative ineffectiveness and two mechanisms of inhibitory activity. Am $\mathrm{f}$ Respir Cell $\mathrm{Mol} \mathrm{Biol}$ 1990;2:263-9.

25 Rinehart AR, Mallaya S, Simon SR. Human $\alpha_{1}$-proteinase inhibitor binds to extracellular matrix in vitro. $A m \mathcal{F}$ Respir Cell Mol Biol 1993;9:666-79. 